\title{
Hydrocephalus in a patient with an unruptured pial arteriovenous fistula: hydrodynamic considerations, endovascular treatment, and clinical course
}

\author{
Jesús A. Morales-Gómez, MD, ${ }^{1}$ Vicente V. Garza-Oyervides, MD,1 José A. Arenas-Ruiz, MD,1 \\ Mariana Mercado-Flores, MD, ${ }^{2}$ C. Guillermo Elizondo-Riojas, MD, PhD, ${ }^{2}$ Frederick A. Boop, MD, ${ }^{3}$ \\ and Ángel Martínez-Ponce de León, MD'
}

\begin{abstract}
${ }^{1}$ Servicio de Neurocirugía and ${ }^{2}$ Centro Universitario de Imagen Diagnóstica, Hospital Universitario "Dr. José Eleuterio González," Monterrey, Nuevo León, México; and 32Department of Neurosurgery, University of Tennessee Health Sciences Center, Memphis, Tennessee
\end{abstract}

\begin{abstract}
Intracranial pial arteriovenous fistulas, also known as nongalenic fistulas, are rare vascular malformations affecting predominantly the pediatric population. Hydrocephalus is an unusual presentation in which the exact pathophysiology is not fully understood. The aim of treatment in these cases is occlusion of the fistula prior to considering ventricular shunting. Here, the authors describe the hydrodynamic considerations of the paravascular pathway and the resolution of hydrocephalus with endovascular treatment of the fistula.
\end{abstract}

https://thejns.org/doi/abs/10.3171/2016.9.PEDS16458

KEY WORDS hydrocephalus; pial arteriovenous fistula; endovascular; hydrodynamic

$\mathrm{I}$ NTRACRANIAL pial arteriovenous fistulas (AVFs), also known as nongalenic fistulas, are rare vascular malformations affecting predominantly the pediatric population. Prevalence remains unknown due to their rarity but is estimated to be between $0.1 / 100,000$ and 1/100,000 from previous studies. ${ }^{23,44}$ The distinct angioarchitectural characteristics include a high-flow shunt of 1 or more feeding arteries to an early draining cortical vein without intervening nidus of a typical arteriovenous malformation. These are distinguished from a dural AVF by the location of the fistula site in the subpial meningeal space, and from a vein of Galen malformation, by the lack of direct involvement of the embryonic median prosencephalic vein. . $^{2,15,24,32,36,43}$

Clinical presentation depends on age, mass effect, hemodynamic steal, or venous hypertension. In the newborn a pial AVF usually presents with congestive heart failure, increasing head circumference, or focal neurological deficit. ${ }^{11,31}$ Adolescents and adults tend to present with headache, seizures, and focal neurological deficit. Acute presentation due to subarachnoid or intracerebral hemorrhage is less common. . $^{1,4,8,16,25,33,37,44}$

Hydrocephalus is an unusual presentation but can be seen in newborns and infants. The exact pathophysiology of this clinical presentation is still unknown but is likely due to the raised venous pressure caused by a high-flow fistula. The difference in the CSF dynamic between the child and the adult might have a significant role in the differing presentations based on age.,.$^{9,29}$

In this article we describe the hydrodynamic considerations in the resolution of hydrocephalus with endovascular treatment of a pial fistula with transarterial embolization using coils and glue ( $N$-butyl cyanoacrylate [NBCA]).

\section{Case Report}

A 4-year-old boy was referred to our hospital for a second medical opinion. He had a history of 2 years of severe cognitive developmental disturbances; 9 months of insidious, intermittent headache and irritability; and an isolated episode of tonic-clonic seizure lasting a few seconds with a postictal period of an hour. Psychomotor and gait disturbances were not noticed by the parents until their 2-year-old son began to surpass his older sibling in neurocognitive development.

The patient was treated with oxcarbazepine and was considered for CSF shunt surgery by another neurosurgeon, a procedure to which the parents did not consent. On our examination the infant was noted to demonstrate remarkable psychomotor retardation, was unable to complete sentences, babbled on occasion, was unable to walk, demonstrated mild somnolence, exhibited bilateral papilledema, and had notable facial venous distention. There were no focal clinical findings in the remaining portion of the neurological examination. 

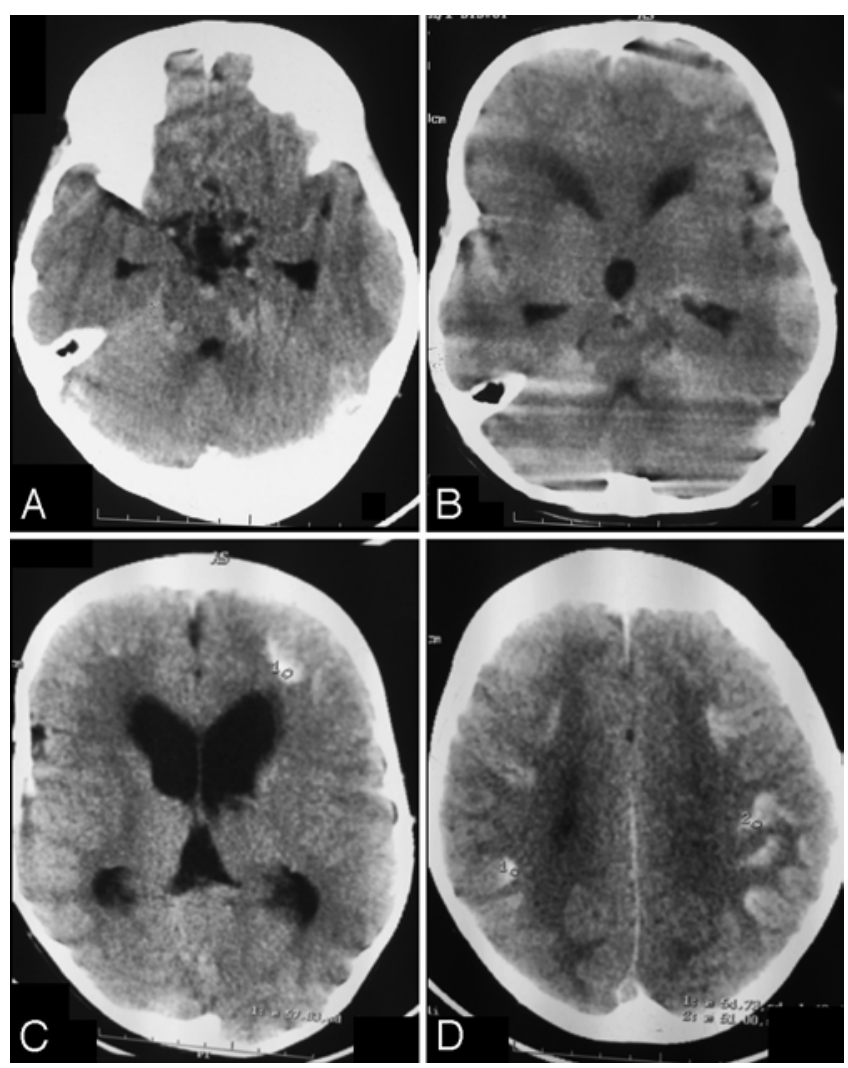

FIG. 1. Unenhanced head CT scans obtained at another institution, showing dilated perimesencephalic (A) and sylvian (B) vessels, supratentorial hydrocephalus with transependymal edema (C), and bilateral and symmetrical hyperdense lesions (D) in the supratentorial juxtacortical areas.

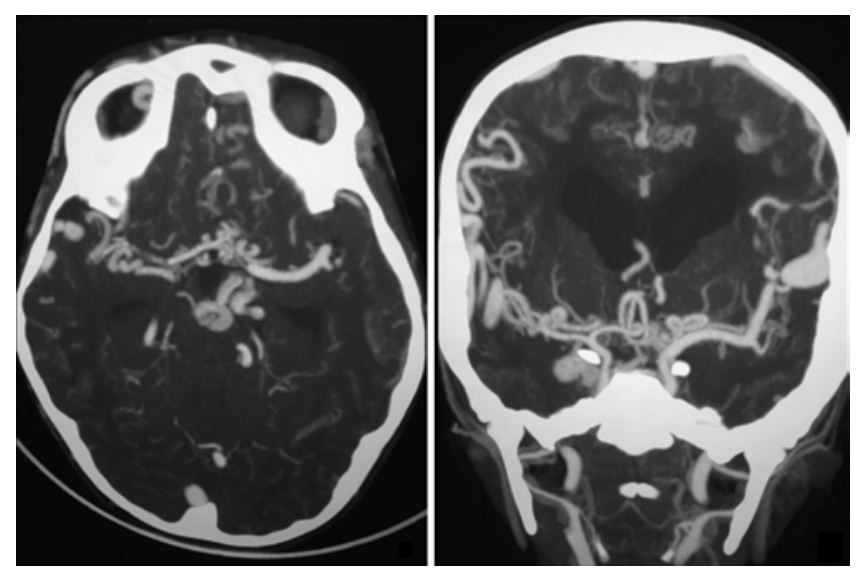

FIG. 2. In the arterial phase, hyperdense, dilated tortuous arterial and venous vessels are shown. Left: The left middle cerebral artery is larger in diameter than the right middle cerebral artery. Right: In the rostral part of the left lateral sulcus, a saccular lesion communicates with a superficial cortical vein associated with dilation of the superficial and deep veins.

CT scans from another institution demonstrated hydrocephalus, transependymal edema, juxtacortical calcifications, and subarachnoid dilated vessels in the sylvian sulcus and perimesencephalic cistern (Fig. 1). A CT angiogram of the head revealed an AVF supplied by a single branch of the left middle cerebral artery with a large intervening aneurysm draining to a cortical vein (Fig. 2).

The child underwent digital subtraction angiography (Fig. 3), which confirmed a pial AVF with an aneurysmal venous dilation between a single feeder, corresponding to
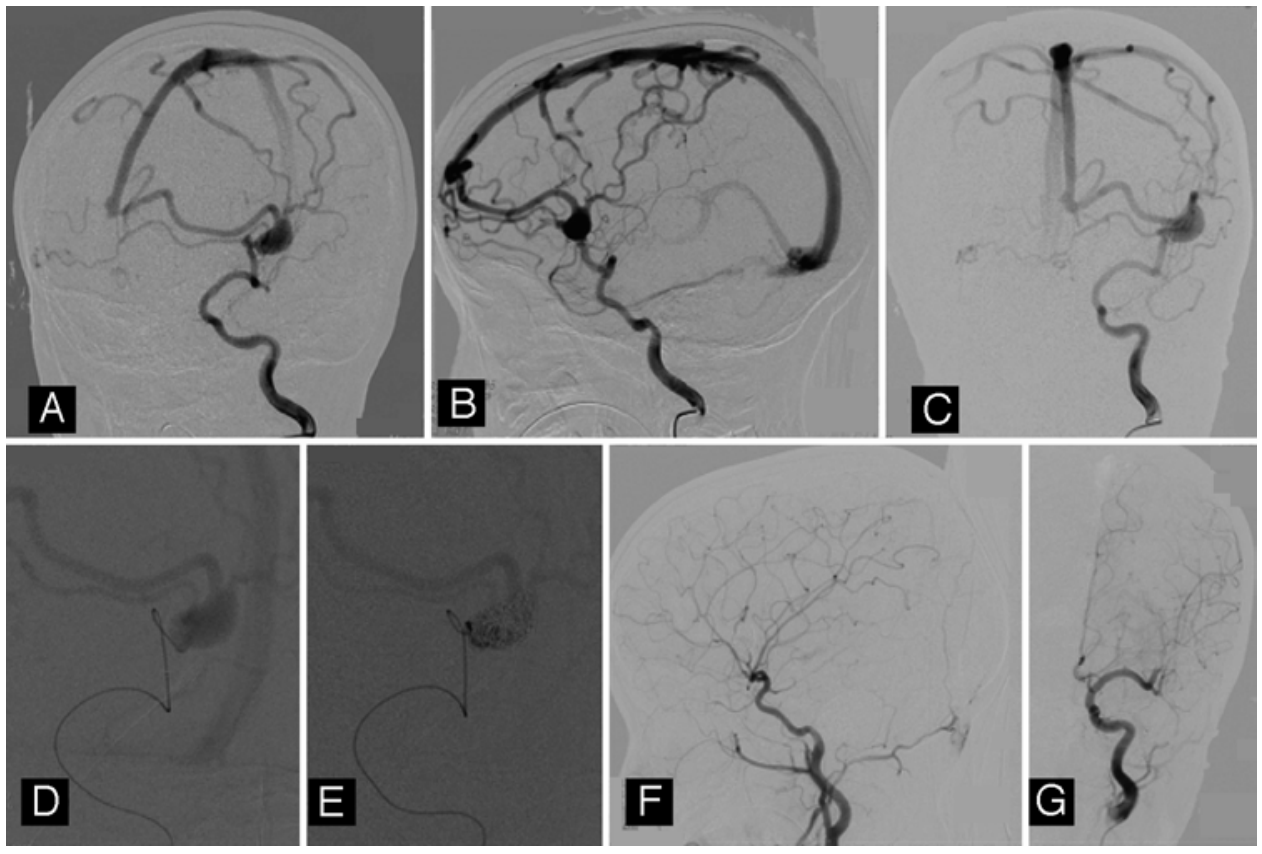

FIG. 3. Catheter angiograms showing a pial AVF with an aneurysmal venous dilation between a single feeder, corresponding to a left $\mathrm{M}_{3}$ afferent artery, and a vein at the sylvian fissure $(\mathbf{A})$, with high efferent drainage to the superior sagittal sinus and retrograde reflux of deep venous system from the confluence of sinuses to both cavernous sinuses (B) and also retrograde reflux of contralateral cerebral veins to petrosal sinus (C). Moreover, there were stenoses (hypoplasia) of both sigmoid sinuses and both jugular bulbs were formed by ipsilateral petrous sinuses. The fistula was excluded from the cerebral circulation by means of embolization of the venous pouch with coils and glue (NBCA, D-G). 

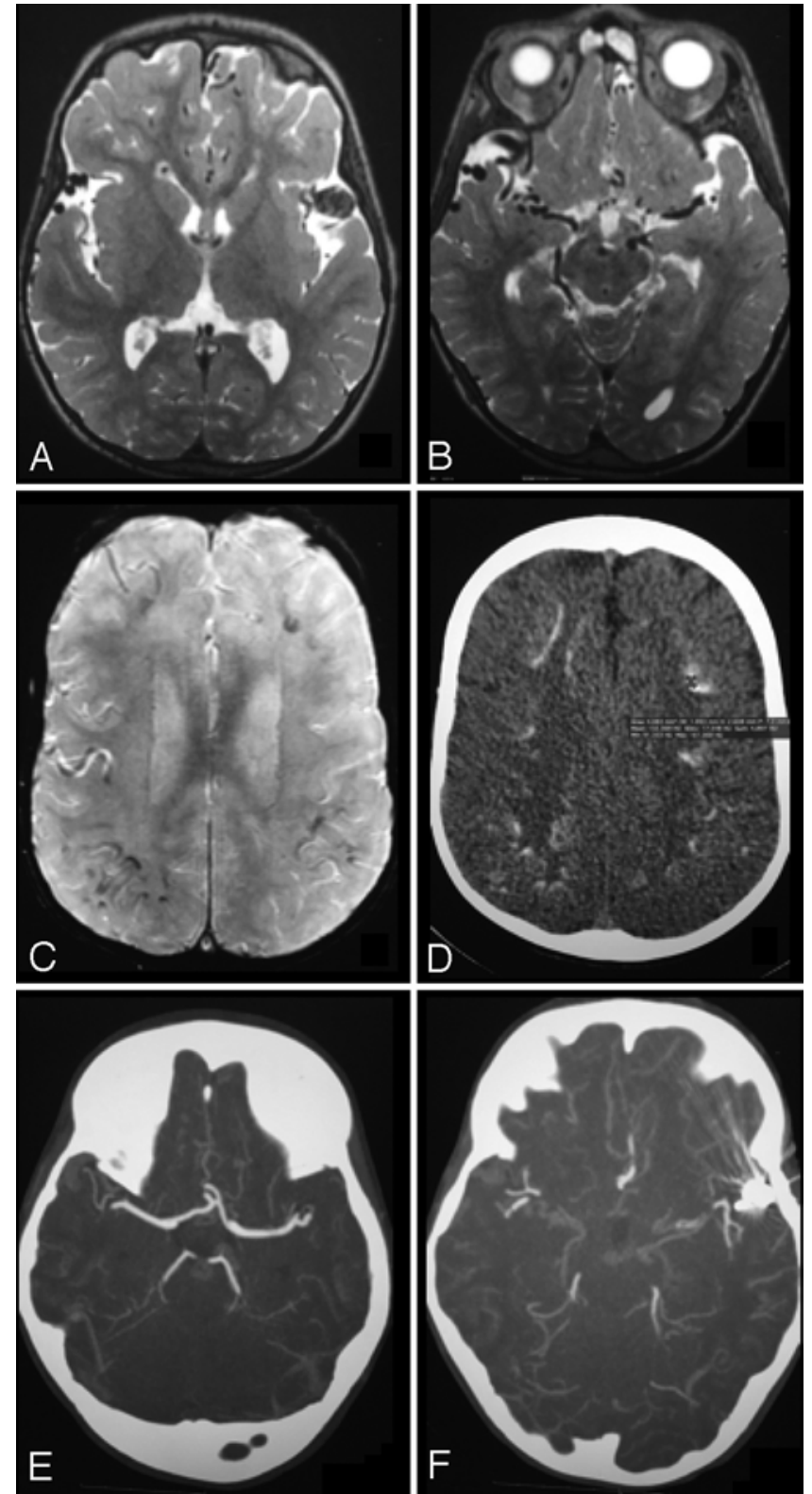

FIG. 4. MR images $(\mathbf{A}-\mathbf{C})$ and 3-month posttreatment $\mathrm{CT}$ angiograms (D-F) demonstrating considerable reduction of hydrocephalus.

a left $\mathrm{M}_{3}$ afferent artery, and a vein at the sylvian fissure, with high efferent drainage to the superior sagittal sinus and retrograde reflux of the deep venous system from the confluence of sinuses to both cavernous sinuses and also retrograde reflux of contralateral cerebral veins to the ipsilateral petrosal sinus. Moreover, there were stenoses (hypoplasia) of both sigmoid sinuses, and both jugular bulbs were formed by ipsilateral petrous sinuses. The fistula was excluded from the cerebral circulation by means of embolization of the venous pouch with coils and glue (NBCA). The angiogram obtained immediately postembolization is shown (Fig. 3).

The child was discharged 3 days after embolization without complications. An MRI study and 3-month posttreatment CT angiogram (Fig. 4) demonstrated consider- able reduction of the hydrocephalus. The patient has recovered well, and his development thus far has been appropriate for his age as assessed by our neuropsychologist.

\section{Discussion}

Similar to vein of Galen malformations, relatively more common high-flow fistulas, the clinical presentation of pial AVF in pediatric patients tends to vary by age. Hydrocephalus and macrocrania have been reported to be between $14.3 \%$ and $38 \%$ in different clinical series. ${ }^{15,24,33,39}$

In patients with pial AVF and mild to moderate hydrocephalus without acute intracranial hypertension, the aim of treatment is occlusion of the fistula, either surgical ${ }^{21,40}$ or endovascular. Ventriculoperitoneal shunting prior to this exclusion decreases the pressure in the ventricles that may result in hygromas, subdural hemorrhage,$^{3}$ or hemorrhage as shown in different clinical scenarios with venous overload and associated hydrocephalus. ${ }^{26,30,34,41}$ This paradigm shift is clearer in vein of Galen malformation treatment in which endovascular obliteration is the first-line option rather than direct management of the hydrocephalus by CSF diversion. ${ }^{10,11,27}$

Endovascular treatment has been reported in other articles to be effective in the obliteration of the fistula, with excellent outcomes in most patients. ${ }^{14,17,38,39,43}$ The technique is challenging because of the high-flow nature of the fistula and because distal migration of embolic agents through the shunt cannot be easily controlled; inadvertent migration of these agents into the veins may result in immediate hemorrhage by venous outflow obstruction..$^{2,13,20,28} \mathrm{We}$ decided to use NBCA in our patient in combination with coils because of our vast experience using this material.

Understanding of CSF physiology is evolving since the bulk flow model. In children, it is well established that communicating hydrocephalus can be caused by vascular dysfunction, such as idiopathic venous outflow resistance, venous sinus collapse, venous thrombosis, and venous outlet stenosis at the skull base associated with craniofacial dysostoses. The exact mechanism, like in the pial AVF, is unclear. ${ }^{5,22}$

In this case, the arteriovenous shunt was considered the cause of hydrocephalus, and therapeutic embolization was planned. We speculate that excessive intracranial venous pressure can affect the paravascular pathway secondary to an inverted hydrodynamic flow.,29 This paravascular pathway may play a significant role as arachnoid granulations lack maturation..$^{27,44}$ This paravascular pathway has already been shown in experimental models, but not in humans, ${ }^{6,18,19}$ as an alternative CSF passage and is believed to depend on hydrodynamics, if there is venous hypertension from venous overload, like in pial AVF, decreased CSF resorption will occur, leading to nonobstructive hydrocephalus. ${ }^{9,12}$

In this case, the dystrophic calcification shown in the images can be an accumulation of waste product in the paravascular space that cannot be washed out because of the inverse hydrostatic pressure ${ }^{29}$ and not only the result of chronic hypoxic insult described by others. $.15,27,29,35,42$ This evolving understanding of CSF dynamics will help us bring better care and make better decisions, but many 
animal models and clinical analyses on hydrocephalus will be needed to fully understand the hydrodynamics.

\section{References}

1. Aguilar M, González A, López A, Gutiérrez I, Durand F, Mayol A: Endovascular treatment of a pial arteriovenous fistula with occipital remodeling secondary to giant torcular dilation. J Child Neurol 26:1015-1020, 2011

2. Alurkar A, Karanam LS, Nayak S, Ghanta RK: Intracranial pial arteriovenous fistulae: diagnosis and treatment techniques in pediatric patients with review of literature. J Clin Imaging Sci 6:2, 2016

3. Alvarez H, Garcia Monaco R, Rodesch G, Sachet M, Krings T, Lasjaunias P: Vein of Galen aneurysmal malformations. Neuroimaging Clin N Am 17:189-206, 2007

4. Arroyo-Fernández FJ, Calderón-Seoane E, Rodríguez-Peña F, Torres-Morera LM: Fluidoterapia intraoperatoria en lactante con insuficiencia cardiaca congestiva por fístula arteriovenosa pial intracraneal. Rev Esp Anestesiol Reanim 63:301-304, 2016

5. Bateman GA, Fiorentino M: Childhood hydrocephalus secondary to posterior fossa tumor is both an intra- and extraaxial process. J Neurosurg Pediatr 18:21-28, 2016

6. Bedussi B, van Lier MG, Bartstra JW, de Vos J, Siebes M, VanBavel E, et al: Clearance from the mouse brain by convection of interstitial fluid towards the ventricular system. Fluids Barriers CNS 12:23, 2015

7. Beggs CB: Venous hemodynamics in neurological disorders: an analytical review with hydrodynamic analysis. BMC Med 11:142, 2013

8. Berenstein A, Ortiz R, Niimi Y, Elijovich L, Fifi J, Madrid $\mathrm{M}$, et al: Endovascular management of arteriovenous malformations and other intracranial arteriovenous shunts in neonates, infants, and children. Childs Nerv Syst 26:1345-1358, 2010

9. Cruz JP, Gandolfo C, Geibprasert S, Krings T: Pediatric vascular malformations of the brain: concepts and classifications, diagnosis and endovascular treatment, in Rossi A (ed): Pediatric Neuroradiology. Berlin: Springer, pp 1-36, 2015

10. d'Avella D, Causin F: Hydrocephalus in vein of Galen malformation. Another paradigm shift in neurosurgery. Acta Neurochir (Wien) 158:1285-1288, 2016

11. García-Mónaco R, Taylor W, Rodesch G, Alvarez H, Burrows $\mathrm{P}$, Coubes $\mathrm{P}$, et al: Pial arteriovenous fistula in children as presenting manifestation of Rendu-Osler-Weber disease. Neuroradiology 37:60-64, 1995

12. Geibprasert S, Pereira V, Krings T, Jiarakongmun P, Lasjaunias P, Pongpech S: Hydrocephalus in unruptured brain arteriovenous malformations: pathomechanical considerations, therapeutic implications, and clinical course. J Neurosurg 110:500-507, 2009

13. Guimaraens L, Casasco A, Sola T, Cuellar H, Miralbes S, Cambra FJ: Endovascular treatment of a pial arteriovenous fistula of a posteroinferior cerebellar artery with a double origin. J Neurointerv Surg 3:233-236, 2011

14. Hermier M, Turjman F, Bozio A, Duquesnel J, Lapras C: Endovascular treatment of an infantile nongalenic cerebral arteriovenous fistula with cyanoacrylate. Childs Nerv Syst 11:494-498, 1995

15. Hetts SW, Keenan K, Fullerton HJ, Young WL, English JD, Gupta N, et al: Pediatric intracranial nongalenic pial arteriovenous fistulas: clinical features, angioarchitecture, and outcomes. AJNR Am J Neuroradiol 33:1710-1719, 2012

16. Hoh BL, Putman CM, Budzik RF, Ogilvy CS: Surgical and endovascular flow disconnection of intracranial pial singlechannel arteriovenous fistulae. Neurosurgery 49:1351-1364, 2001
17. Hung PC, Wang HS: Successful endovascular treatment of cerebral arteriovenous fistula. Pediatr Neurol 27:300-302, 2002

18. Iliff JJ, Wang M, Liao Y, Plogg BA, Peng W, Gundersen GA, et al: A paravascular pathway facilitates CSF flow through the brain parenchyma and the clearance of interstitial solutes, including amyloid $\beta$. Sci Transl Med 4:147ra111, 2012

19. Iliff JJ, Wang M, Zeppenfeld DM, Venkataraman A, Plog BA, Liao Y, et al: Cerebral arterial pulsation drives paravascular CSF-interstitial fluid exchange in the murine brain. J Neurosci 33:18190-18199, 2013

20. Jayaraman MV, McTaggart RA, Sachs GM, Doberstein CE: Cerebellar pial arteriovenous malformations presenting with medullary venous hypertension: imaging and endovascular treatment. J Neurointerv Surg 2:38-40, 2010

21. Jouibari MF, Zadeh MZ, Khadivi M, Khoshnevisan A, Moazzeni K, Abdollahzade S: Pial arteriovenous fistula with giant varices: report of two cases with good surgical outcome. J Cerebrovasc Endovasc Neurosurg 16:98-103, 2014

22. Kahle KT, Kulkarni AV, Limbrick DD Jr, Warf BC: Hydrocephalus in children. Lancet 387:788-799, 2016

23. Kraneburg UM, Nga VD, Ting EY, Hui FK, Lwin S, Teo C, et al: Intracranial pial arteriovenous fistula in infancy: a case report and literature review. Childs Nerv Syst 30:365-369, 2014

24. Lasjaunias P, terBrugge KG, Berenstein A: Surgical Neuroangiography: Vol. 3: Clinical and Interventional Aspects in Children. Berlin: Springer, 2007

25. Madsen PJ, Lang SS, Pisapia JM, Storm PB, Hurst RW, Heuer GG: An institutional series and literature review of pial arteriovenous fistulas in the pediatric population: clinical article. J Neurosurg Pediatr 12:344-350, 2013

26. Meila D, Grieb D, Melber K, Jacobs C, Maslehaty H, Petridis A, et al: Hydrocephalus in vein of Galen malformation: etiologies and therapeutic management implications. Acta Neurochir (Wien) 158:1279-1284, 2016

27. Metoki T, Mugikura S, Higano S, Ezura M, Matsumoto Y, Hirayama K, et al: Subcortical calcification on CT in dural arteriovenous fistula with cortical venous reflux. AJNR Am J Neuroradiol 27:1076-1078, 2006

28. Nakiri GS, Abud TG, Oliveira RS, Santos AC, Machado HR, Abud DG: Endovascular treatment of intracranial pial arteriovenous fistula. Arq Neuropsiquiatr 68:463-465, 2010

29. Orešković D, Klarica M: Development of hydrocephalus and classical hypothesis of cerebrospinal fluid hydrodynamics: facts and illusions. Prog Neurobiol 94:238-258, 2011

30. Panigrahi S, Mishra SS, Das S, Parida DK: Intracerebral pial arteriovenous fistula with large venous varix: A rare case report. Surg Neurol Int 4:22, 2013

31. Paramasivam S, Toma N, Niimi Y, Berenstein A: De novo development of dural arteriovenous fistula after endovascular embolization of pial arteriovenous fistula. J Neurointerv Surg 5:321-326, 2013

32. Requejo F, Jaimovich R, Marelli J, Zuccaro G: Intracranial pial fistulas in pediatric population. Clinical features and treatment modalities. Childs Nerv Syst 31:1509-1514, 2015

33. Rodesch G, Malherbe V, Alvarez H, Zerah M, Devictor D, Lasjaunias P: Nongalenic cerebral arteriovenous malformations in neonates and infants. Review of 26 consecutive cases (1982-1992). Childs Nerv Syst 11:231-241, 1995

34. Sugimoto T, Park YS, Nakagawa I, Nishimura F, Motoyama $\mathrm{Y}$, Nakase H: Effectiveness of intraoperative indocyanine green videoangiography in direct surgical treatment of pediatric intracranial pial arteriovenous fistula. J Neurosurg Pediatr 15:55-59, 2015

35. Tabatabai SA, Zadeh MZ, Habibi Z, Meybodi AT, Hashemi $\mathrm{M}$ : Intracerebral atypical calcification in nongalenic pial arteriovenous fistula: a case report. Cases J 1:335, 2008 
36. Upchurch K, Feng L, Duckwiler GR, Frazee JG, Martin NA, Viñuela F: Nongalenic arteriovenous fistulas: history of treatment and technology. Neurosurg Focus 20(6):E8, 2006

37. Viñuela F, Drake CG, Fox AJ, Pelz DM: Giant intracranial varices secondary to high-flow arteriovenous fistulae. J Neurosurg 66:198-203, 1987

38. Walcott BP, Smith ER, Scott RM, Orbach DB: Pial arteriovenous fistulae in pediatric patients: associated syndromes and treatment outcome. J Neurointerv Surg 5:10-14, 2013

39. Weon YC, Yoshida Y, Sachet M, Mahadevan J, Alvarez H, Rodesch G, et al: Supratentorial cerebral arteriovenous fistulas (AVFs) in children: review of 41 cases with 63 non choroidal single-hole AVFs. Acta Neurochir (Wien) 147:17-31, 2005

40. Yamashita K, Ohe N, Yoshimura S, Iwama T: Intracranial pial arteriovenous fistula. Neurol Med Chir (Tokyo) 47:550-554, 2007

41. Yang J, Kwon OK, Oh CW, Hwang G, Song KS, Lee YJ, et al: Surgical flow disconnection of cerebral pial dual-channel arteriovenous fistula with a large varix: the role of antiplatelet agent or anti-coagulation therapy. Childs Nerv Syst 29:1021-1025, 2013

42. Yang MS, Chen CC, Cheng YY, Yeh DM, Lee SK, Tyan YS: Unilateral subcortical calcification: a manifestation of dural arteriovenous fistula. AJNR Am J Neuroradiol 26:11491151,2005

43. Youn SW, Han MH, Kwon BJ, Kang HS, Chang HW, Kim BS: Coil-based endovascular treatment of single-hole cerebral arteriovenous fistulae: experiences in 11 patients. World Neurosurg 73:2-10, e1, 2010
44. Zuccaro G, Argañaraz R, Villasante F, Ceciliano A: Neurosurgical vascular malformations in children under 1 year of age. Childs Nerv Syst 26:1381-1394, 2010

\section{Disclosures}

The authors report no conflict of interest concerning the materials or methods used in this study or the findings specified in this paper.

\section{Author Contributions}

Conception and design: Morales-Gómez. Acquisition of data: Morales-Gómez, Garza-Oyervides. Analysis and interpretation of data: Morales-Gómez, Mercado-Flores, Elizondo-Riojas, Boop, Martínez-Ponce de León. Drafting the article: Morales-Gómez, Mercado-Flores, Elizondo-Riojas. Critically revising the article: Morales-Gómez, Garza-Oyervides, Boop, Martínez-Ponce de León. Reviewed submitted version of manuscript: MoralesGómez, Garza-Oyervides, Arenas-Ruiz, Boop, Martínez-Ponce de León. Approved the final version of the manuscript on behalf of all authors: Morales-Gómez. Administrative/technical/material support: Morales-Gómez, Martínez-Ponce de León. Study supervision: Morales-Gómez, Martínez-Ponce de León.

\section{Correspondence}

Jesús A. Morales-Gómez, Hospital Universitario "Dr. José Eleuterio González," Universidad Autónoma de Nuevo León, Neurosurgery Department, Francisco y Madero S/N, Monterrey, Nuevo León 64440, México. email: chuy_morales@hotmail.com. 